\title{
POLÍTICA DE COTAS NA EDUCAÇÃO SUPERIOR: LUTASE DESAFIOS NO COMBATE À POBREZA E DESIGUALDADE DE ESTUDANTES NEGROS
}

\author{
JoELMA INÊS EVANGELISTA \\ Carina Elisabeth Maciel \\ Universidade Federal de Mato Grosso do Sul (UFMS), Campo Grande, \\ Mato Grosso do Sul, Brasil
}

\begin{abstract}
Resumo: Este artigo tem como objetivo estabelecer uma discussão sobre a situação de vulnerabilidade de estudantes negros/as e enfatizar a importância da política de cotas como uma forma de democratizar o acesso desses jovens à educação superior. A metodologia utilizada para a produção estruturou-se por meio de análise bibliográfica e dados públicos, que permitissem relacionar o contexto da educação e pobreza com as discussões sobre o acesso à educação superior de pessoas negras. A partir da discussão, foi possível constatar que o acesso de estudantes negros é prejudicado por fatores socioeconômicos e históricos que os colocam, na comparação com os estudantes brancos, em condições inferiores de acesso. Nesse sentido, a política de cotas representa um meio para que esses estudantes possam competir pelas vagas na educação superior com aqueles que tiveram condições semelhantes, tornando, portanto, o processo seletivo mais democrático.
\end{abstract}

Palavras-chave: Estudantes Negros/as. Educação Superior. Acesso. Desigualdade.

\section{INTRODUÇÃO}

A educação, garantida como um direito de todos no artigo 205 da Constituição Federal de 1988, se materializa como um dos principais meios de minimizar as desigualdades que assolam a sociedade, principalmente para estudantes negros que se encontram na linha da pobreza, em situação de vulnerabilidade. A ideia da educação como meio capaz de transformar e promover uma melhora da condição social do indivíduo transforma-se em uma válvula de escape, onde o estudante pode ou não conseguir superar essas fraturas, uma vez que a melhora da condição social do indivíduo não está apenas relacionada com a educação, pois compreende-se que há outros fatores socioeconômicos, ao longo do percurso, projetando barreiras na vida desses estudantes.

O cenário da educação, segundo Garcia (2007), é constituído por vários elementos, entre eles estão as condições socioeconômicas dos estudantes, uma vez que o meio social interfere em seu desempenho escolar provocando alterações na trajetória 
acadêmica, desde a educação básica até a educação superior. Para Cordeiro (2017), no caso dos estudantes negros e pobres, o agravante é ainda maior devido aos mecanismos excludentes da sociedade que ocasionam maiores desigualdades, pois além de não possuir as mesmas condições econômicas de outros estudantes de classe alta, ainda precisam ultrapassar a barreira do preconceito racial e fortalecimento de sua identidade como negro.

Este artigo tem como objetivo estabelecer uma discussão sobre a situação de vulnerabilidade de estudantes negros/as e enfatizar a importância da política de cotas como uma forma de democratizar o acesso desses jovens à educação superior. Assim, farse-á uma comparação do acesso desses jovens na educação superior antes e depois da implantação da política de cotas no Brasil, buscando relacionar dados de raça e renda como recorte para a discussão. A metodologia utilizada para a elaboração do artigo foi organizada por meio de pesquisa bibliográfica, análise de dados públicos e de entrevistas sobre o tema, que permitiram relacionar o contexto da educação e pobreza com as discussões sobre 0 acesso à educação superior de pessoas negras.

Para apresentar as discussões, os dados e as análises, o artigo foi organizado com a seguinte estrutura: $O$ acesso à educação superior em 2010: Análise por meio das categorias de renda e raça, em que se estabelece a relação do acesso às Instituições de Educação Superior (IES) com a renda familiar per capita e de acordo com a raça/cor, com o intuito de demonstrar como o ingresso (ou a opção) nos cursos de graduação pode estar relacionado com as condições socioeconômicas familiares dos estudantes. Os dados utilizados se referem ao estudo feito pelo Instituto de Pesquisa Econômica Aplicada (IPEA) no ano de 2010, pois expressam o acesso desses grupos antes da aprovação da política de cotas no Brasil.

No item "Política de cotas: Uma ação afirmativa na luta contra as desigualdades sociais", fomenta-se a discussão sobre a necessidade das cotas na educação superior e são apresentadas entrevistas que demonstram opiniões contrárias e a favor das cotas, analisadas por meio da Lei ${ }^{\circ} 12.711 / 2012$. Destaca-se, por fim os dados do Censo da Educação Superior entre os anos de 2013 a 2017, utilizando o percentual de matrículas na educação superior, para ressaltar que houve um aumento das matrículas após a implantação da política de cotas nas Universidades Federais.

\section{O ACESSO À EDUCAÇÃO SUPERIOR EM 2010: ANÁLISE POR MEIO DAS CATEGORIAS DE RENDA E RAÇA}

0 acesso à educação superior, por muito tempo restrito a uma determinada parcela da população, está relacionado às condições econômicas familiares dos estudantes. Em alguns casos, os jovens não conseguem completar a educação básica e chegar aos IES porque ingressam no mercado de trabalho mais cedo para tentar sanar necessidades básicas como: alimentação, moradia e vestimenta, pois a estrutura familiar pode ou não interferir de forma negativa ou até mesmo porque os progenitores da família, mesmo tendo vínculo empregatício, nem sempre conseguem proporcionar o básico para a mesma, uma vez que a condição da renda per capita familiar também está 
associada a outros fatores como, por exemplo, grau de escolaridade, raça, gênero e, até mesmo, o desenvolvimento da lógica do mercado, gerando, assim, uma condição de desigualdade entre as classes.

Apresentar o contexto de acesso à educação de estudantes negros no ano de 2010 possibilita a identificação de fraturas importantes, determinantes de desigualdades no acesso e na permanência desse grupo na educação superior. Tal condição expressa a necessidade de políticas específicas para o acesso de estudantes negros à educação superior.

Essa condição de desigualdade, para Rousseau (2017), se perpetua e acentua com a exploração do homem pelo homem na sociedade moderna, mesmo tendo como princípio que a desigualdade entre si está presente na sociedade desde o momento em que o homem primitivo passa a se organizar em sociedade e fundar as primeiras cidades. Essa forma de organização social está condicionada a evidenciar a pobreza e as desigualdades entre os diferentes grupos. Para Duarte (2012, p. 33), "Fenômeno presente nos agrupamentos humanos desde o princípio dos tempos, a pobreza é uma experiência humana e social que acompanha a existência do homem sobre a terra desde 0 estado natural até os dias atuais".

Ao observar o desenvolvimento econômico ao longo do tempo, é possível compreender que 0 fortalecimento do capitalismo contribuiu significativamente para 0 aprofundamento das desigualdades, a classe operária contribuiu com esse processo na subordinação, mas foram essenciais para o desenvolvimento do sistema e ao mesmo tempo reféns, condenados a exploração e a condição de consumidor mínimo (CASTEL, 2003).

As condições socioeconômicas, em particular a renda, têm sido apontadas como fator de alta correlação com o desempenho educacional dos estudantes. No caso do acesso à educação superior que, via de regra, ocorre com o advento da maioridade, a necessidade de gerar renda e ingressar no mercado de trabalho pode constituir empecilho à continuidade nos estudos. Assim como foi mencionado, tal situação é agravada pelo fato de que parcela significativa dos jovens brasileiros não consegue concluir 0 ensino médio na idade adequada, o que dificulta ainda mais a continuidade nos estudos mediante ingresso na educação superior (IPEA, 2014, p. 18-19).

Quando a discussão está voltada para o acesso à educação superior de estudantes negros, o problema é agravado, porque além de buscar a superação da condição de pobreza esses jovens ainda têm que lidar com o racismo que perpetua na sociedade, [...] "ser negro significa ainda, ganhar pouco e em profissões de baixa qualificação. A pele negra significa mais uma barreira no mercado de trabalho, que discrimina trabalhadores pela aparência, ou seja, pelo fenótipo" (BITTAR; CORDEIRO; ALMEIDA, 2007, p. 146).

A trajetória histórica brasileira nos mostra que desde a Constituição de 18240 acesso à educação era prioridade da elite, uma vez que no período em questão a população negra era tida como mercadoria para mão de obra e não gozava de direitos como cidadãos. Passados quase 200 anos, mesmo com a abolição em 1888 e todas as mudanças constitucionais, as desigualdades permanecem presentes. 
[...] em cada período o "não-lugar social" relegado aos/às afro-brasileiros/as e as "desvantagens sociais" vão se acumulando em suas trajetórias educacionais e profissionais, que são resultado do racismo à brasileira e constituem o retrato da estratificação social no país (CORDEIRO, 2017, p. 50).

Mediante essas asserções, faz-se necessário promover medidas de ação afirmativa que proporcionem uma democratização do acesso, que promovam políticas públicas educacionais que possibilitem estratégias, para que esses jovens em condição de vulnerabilidade venham a ter acesso, permanência e concluam uma graduação, constatação essa que nem sempre acontece. Para Cordeiro (2017, p. 25),„Um dos níveis de ensino mais elitizados no Brasil é a educação superior, que ainda não consegue atender a demanda em geral da população, sendo poucos/as os/as afro-brasileiros/as que ingressam, permanecem e concluem uma graduação".

A partir das considerações de Munanga (2001), é possível compreender que as políticas universais não são suficientes para minimizar as discrepâncias entre brancos e negros na sociedade. Quando a raça e a renda são associadas, essas diferenças ficam ainda mais evidentes. Uma pesquisa produzida pelo Instituto de Pesquisa Econômica Aplicada (IPEA) aborda a evolução do acesso de jovens de 18 a 24 anos na educação superior do Brasil entre os anos de 2007-2010. Para tanto, a pesquisa leva em consideração aspectos como raça, renda, localização regional. No entanto, nos dados apresentados relacionados ao quesito raça/cor, o instituto optou por utilizar apenas os dados referentes ao ano de 2010, visto que em suas análises houve um considerável aumento de pessoas autodeclaradas como negras, permitindo assim que se possa desenvolver a análise do acesso da população negra na educação superior dois anos antes da implantação da Lei n. $.12 .711 / 2012$.

Gráfico 1-Taxa de frequência líquida na educação superior, segundo as faixas de renda domiciliar per capta (2010)

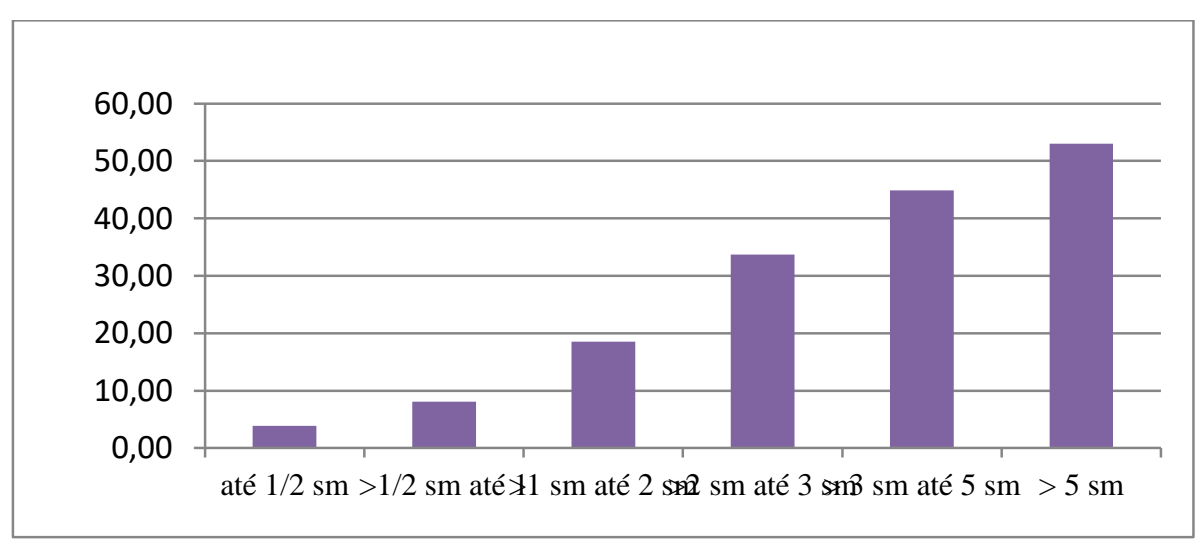

Fonte: IPEA, 2014. 
A partir do Gráfico 1, é possível observar que o acesso à educação superior possui uma grande variação, de acordo com a renda per capita domiciliar, sendo que em domicílios com renda superior a 5 salários mínimos (SM) cerca de $53 \%$ desses jovens conseguem ter acesso aos IES. Já aqueles com renda de até $1 / 2 \mathrm{SM}, 0$ acesso corresponde a 3,9\%. Pode-se estabelecer uma relação dessa renda per capita familiar a partir do que foi discutido acima, visto que os jovens de famílias carentes têm maiores dificuldades em concluir a educação básica e chegar aos cursos de graduação, tendo que optar pelo trabalho diário e o estudo noturno, ou até mesmo não estudar para trabalhar e garantir sua sobrevivência.

São condições que aqueles que vivem em domicílios com renda familiar per capita mais alta não precisam superar. Sendo assim, as chances desses jovens concluírem o ensino médio sem precisar trabalhar, portanto, com tempo dedicado ao estudo e, em alguns casos, também poderem frequentar cursinhos preparatórios para os processos seletivos da educação superior, contribuem para que estejam passos à frente daqueles que não possuem as mesmas condições.

A tabela 1 busca, por meio da taxa de frequência na educação superior e segundo cor/raça no ano de 2010, analisar as desigualdades, tanto no acesso quanto na frequência dos jovens de 18 a 24 anos.

Tabela 1- Taxa de frequência à educação superior da população de 18 a 24 anos, segundo cor/raça em \% (2010)

\begin{tabular}{lccc}
\hline & a) branca & b) preta & c) parda \\
\hline Taxa de frequência líquida & 20,8 & 7,3 & 8,4 \\
Taxa de frequência pregressa & 7,4 & 2,6 & 2,6 \\
Taxa de acesso à educação superior & 28,1 & 9,9 & 11,1 \\
\hline
\end{tabular}

Fonte: IPEA, 2014

A frequência de estudantes negros à educação superior em 2010, antes das cotas para acesso à educação superior, apresenta uma desvantagem enorme para estudantes pretos, indicando a necessidade de políticas específicas para esse grupo:

0 acesso à educação superior, segundo a variável étnica, também evidencia profundas desigualdades entre os jovens brasileiros. 0 hiato existente entre brancos, de um lado, e pretos/ pardos, de outro, pode ser constatado pelos dados da tabela [...] Conforme mostra a tabela, jovens pardos e pretos têm desvantagem de $60 \%$ a $65 \%$ em relação a brancos, no que concerne ao acesso à educação superior, considerando-se para tanto os que frequentavam e aqueles que tiveram acesso a este nível de ensino (IPEA, 2014, p. 20-21).

0 acesso não envolve somente 0 ingresso, mas também a permanência de estudantes em seus respectivos cursos. Os dados de 2010 expressam uma relação que determina a baixa frequência de estudantes pretos na educação superior, qual seja: cor e 
renda per capita. Em 2012, a política aprovada, considerou essa relação ao determinar as linhas pelas quais os candidatos negros participarão do processo de seleção.

Gráfico 2- Taxa de frequência líquida na educação, segundo a cor/etnia e faixa de renda em \% (2010)

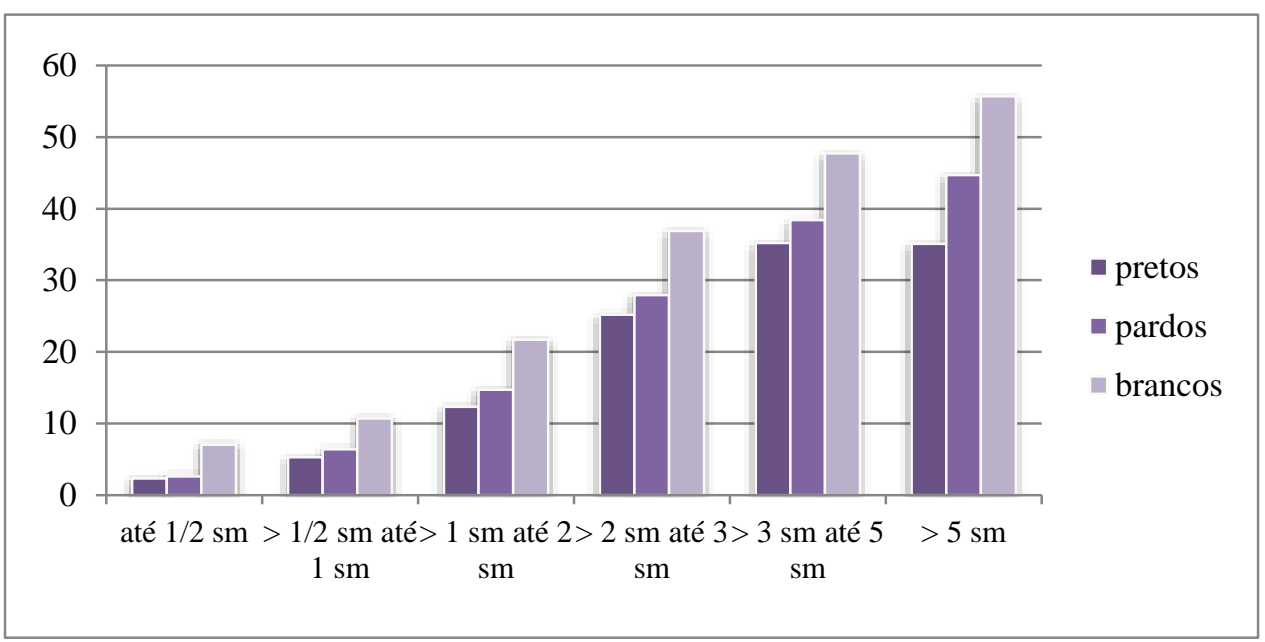

Fonte: IPEA, 2014.

No Gráfico 2, quando associado à cor/etnia e a faixa de renda, é possível observar que o número de brancos com renda de $1 / 2 \mathrm{SM}$ é menor com relação à de pretos e pardos. Logo, quanto mais aumenta a renda per capita, maior fica a discrepância entre brancos e pretos/ pardos, pois o número de pessoas pretas/pardas com renda de 3 a 5 SM é menor em comparação aos brancos.

As desigualdades relativas à apropriação da renda também são bastante pronunciadas quando se desagrega a população segundo a variável etnia/cor. A proporção de brancos com renda domiciliar per capita de até 1 SM era bastante inferior à de pretos e pardos. Enquanto os primeiros somavam $48 \%$, estes últimos atingiam, respectivamente, $72 \%$ e $73 \%$ do total. Também eram muito desiguais as proporções de jovens com renda acima de $2 \mathrm{SMs}$, entre os grupos étnicos selecionados. Entre brancos, a proporção era de cerca de $23 \%$, mas entre pretos/pardos sequer chegava a $8 \%$ do total. (IPEA, 2014, p. 23).

Diante dos dados apresentados pelo IPEA (2014), é possível constatar que o acesso à educação superior de estudantes negros é inferior quando comparado com os estudantes brancos. As diferenças se acentuam quando o quesito renda per capita é asso ciada à raça/cor e, portanto, as desigualdades que precisam ser transpostas pelos 
negros pobres acabam sendo maiores do que as enfrentadas por brancos pobres. Esses desequilíbrios fazem com que se perpetuem desigualdades na sociedade e contribuam para que negros/as continuem ocupando cargos com salários reduzidos e permaneçam na condição de classe dominada/operária na sociedade.

Compreende-se, a partir da análise dessas desigualdades, a necessidade da implementação da política de cotas como uma forma de fomentar 0 acesso dos negros à educação superior, contribuindo para aumentar as chances desse grupo ascender na condição de empregabilidade e de vida e que, por meio do conhecimento desenvolvido, possa lutar por políticas sociais de cunho étnico-raciais.

\section{POLITICA DE COTAS: UMA AÇÃO AFIRMATIVA NA LUTA CONTRA AS DESIGUALDADES SOCIAIS}

A política de cotas foi aprovada como lei no governo da presidente Dilma Vana Roussef, que governou o Brasil entre os anos de 2011-2016/interrompido, em 29 de agosto de 2012 por meio da Lei $n .012 .711$. Essa conquista teve grande participação do movimento negro que há anos tem lutado por melhorias na condição de vida da população negra, resultando em uma série de medidas de ações afirmativas que o Brasil assumiu após sua participação na Conferência de Durban em 2001 na África do Sul, a I Conferência Mundial contra o Racismo, a Discriminação Racial, a Xenofobia e as Formas Conexas de Intolerância.

As IES devem, segundo a Lei $n^{\circ} 12.711 / 2012$, reservar em todos os seus processos seletivos $50 \%$ das vagas para a política de cotas, sendo seu público alvo, segundo o artigo $1^{\circ}$, estudantes que tenham cursado todo o ensino médio em escola pública, com recorte de renda per capita de 1,5 salário mínimo. 0 estudante também pode decidir pela opção sem recorte de renda, e 0 artigo $3^{\circ}$ da mesma lei dispõe sobre a reserva das vagas para pretos, pardos, indígenas de acordo com a densidade demográfica de pessoas autodeclaradas na Unidade Federativa (UF) das IES, podendo ou não optar pelas vagas com recorte de renda. 0 gráfico abaixo demonstra de forma geral como ficou a divisão das vagas reservadas, as IES deveriam em seus processos seletivos reservar aos poucos $25 \%$ do total de vagas tendo até 4 anos para atingir a meta de $50 \%$. 
Gráfico 3 - Porcentagem de reserva de vagas segundo a Lei $n . .0$ 12.711/2012

- Ampla concorrência

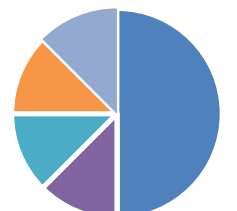

- L1 - Candidatos com renda familiar bruta per capita igual ou inferior a 1,5 salário mínimo que tenham cursado integralmente o ensino médio em escolas públicas

- L2 - Candidatos autodeclarados pretos, pardos ou indígenas, com renda familiar bruta per capita igual ou inferior a 1,5 salário mínimo e que tenham cursado integralmente o ensino médio em escolas públicas

- L3 - Candidatos que, independentemente da renda (art. 14, II, Portaria Normativa $n^{\circ} 18 / 2012$ ), tenham cursado integralmente o ensino médio em escolas públicas

L4 - Candidatos autodeclarados pretos, pardos ou indígenas que, independentemente da renda (art. 14, II, Portaria Normativa $n^{\circ} 18 / 2012$ ), tenham cursado integralmente o ensino médio em escolas públicas

Fonte: MACEDO, 2018.

Em 2016, foi acrescentada à política de cotas, por meio da redação do Artigo 30 dada pela Lei $n$. . 13.409 , o percentual de reserva de vagas para pessoas com deficiência nos processos seletivos.

Antes de sua criação, a política já sofria críticas com relação ao público alvo de pessoas negras, mesmo a lei não sendo apenas destinada à população negra em específico, as críticas decorrem de caráter meritocrático a princípios constitucionais como: "Todos são iguais perante a lei", ou utilizam argumentos de que as cotas, acabam por inferio rizar a população negra, outras decorrem do racismo presente na sociedade, essa resistência à ação afirmativa frequentemente está relacionada ao desconhecimento da lei e a forma como nosso país foi estruturado, uma vez que “[...] as políticas universalistas, quando empregadas em sociedades autoritárias e fortemente estratificadas como é a nossa, não conseguem romper os iníquos mecanismos inerciais produtores de exclusão ou de inserção precarizada" (SISS, 2003, n.p.).

Para Munanga (2002), essas medidas podem ser consideradas como uma forma de discriminação positiva, baseada no princípio de tratar de maneira desigual os excluídos para alcançar a igualdade, sua asserção vem de encontro com a definição de ação afirmativa da Secretária Nacional de Políticas de Promoção de Igualdades Raciais (SEPPIR):

As ações afirmativas no Brasil partem do conceito de equidade expresso na constituição, que significa tratar os desiguais de forma desigual, isto é, oferecer estímulos a todos aqueles que não tiveram igualdade de oportunidade devido a 
discriminação e racismo. Uma ação afirmativa não deve ser vista como um benefício, ou algo injusto. Pelo contrário, a ação afirmativa só se faz necessária quando percebemos um histórico de injustiças e direitos que não foram assegurados (SEPPIR, 2018, n. p.).

Ou seja, em uma sociedade que sofre com desigualdade é necessário que o Estado proporcione medidas de inclusão, para que essas pessoas não fiquem apenas às margens da sociedade, e desigualdades não se perpetuem. As ações afirmativas configuram-se como medidas de caráter temporário e focalizadas, sendo, segundo Almeida (2009, p.56), [...] uma forma de atender aos grupos considerados excluídos de algum direito, porém não a única forma de intervir para garantir-lhes 0 acesso à educação.

Com 0 intuito de analisar as críticas que envolvem a política de cotas, foram pesquisados por Mandetta (2017), na mídia eletrônica, reportagens e entrevistas que se posicionassem e argumentassem contra e a favor da política de cotas, sendo possível compreender quais os principais fatores que influenciam o posicionamento da população com relação à ação afirmativa.

Quadro 1- Argumentos contra a política de cotas

\begin{tabular}{|c|c|c|}
\hline Fonte/Referência & Argumentos & Análise por meio da Lei \\
\hline $\begin{array}{c}\text { SuperVestibular } \\
<\text { http://vestibular.mu } \\
\text { ndoeducacao.bol.uol. } \\
\text { com.br/cotas/argum } \\
\text { entos-contra-as- } \\
\text { cotas.htm> }\end{array}$ & $\begin{array}{l}\text { "A Lei de Cotas náo foi sancionada como } \\
\text { parte de um plano para melhorar a } \\
\text { educação no país, o que a torna um tapa } \\
\text { buracos da rede pública de ensino". }\end{array}$ & $\begin{array}{l}\text { Apesar de realmente não } \\
\text { acompanhar um plano de } \\
\text { educação, no art. 7.o a lei traça um } \\
\text { prazo de } 10 \text { anos. Após esse tempo } \\
\text { a lei deve ser revisada. }\end{array}$ \\
\hline $\begin{array}{l}\text { SuperVestibular } \\
\text { <http://vestibular.mu } \\
\text { ndoeducacao.bol.uol. } \\
\text { com.br/cotas/argum } \\
\text { entos-contra-as- } \\
\text { cotas.htm> }\end{array}$ & $\begin{array}{l}\text { "Inconstitucionalidade da lei, já que } \\
\text { segundo o artigo 5o da Constituição } \\
\text { Federal brasileira somostodosiguais, sem } \\
\text { distinção de qualquer natureza. Deste } \\
\text { modo a reserva de cotas somente } \\
\text { confirmaria a segregação social e racial } \\
\text { existente no país". }\end{array}$ & $\begin{array}{l}\text { A lei } 12.711 / 2012 \text { difere vagas para } \\
\text { negros, pardos e indígenas que } \\
\text { estudaram todo o ensino médio } \\
\text { em escolas públicas, ou seja, } \\
\text { realmente difere o tratamento } \\
\text { geral desses com a ampla } \\
\text { concorrência. }\end{array}$ \\
\hline $\begin{array}{l}\text { SuperVestibular } \\
<\text { <ttp://vestibular.mu } \\
\text { ndoeducacao.bol.uol. } \\
\text { com.br/cotas/argum } \\
\text { entos-contra-as- } \\
\text { cotas.htm> }\end{array}$ & $\begin{array}{l}\text { "As cotas raciais sem critérios econômicos } \\
\text { também podem beneficiar negros que } \\
\text { estudaram em escola particular e } \\
\text { possuem renda alta". }\end{array}$ & $\begin{array}{l}\text { A lei traz um recorte econômico } \\
\text { para as vagas cotistas. No art. } 10 \text { a } \\
\text { lei destinaas vagas para estudantes } \\
\text { que tenham cursado } \\
\text { integralmente o ensino médio em } \\
\text { escolas públicas e dá preferência } \\
\text { aos estudantes com renda familiar } \\
\text { inferior a } 1,5 \text { salário mínimo per } \\
\text { capita. Além disso, a lei não é } \\
\text { destinada apenas aos negros, mas } \\
\text { também para indígenas, pardos e } \\
\text { pessoas com deficiências. }\end{array}$ \\
\hline
\end{tabular}

Fonte: MANDETTA, 2017. 
A busca pelos argumentos, realizada na pesquisa de Mandetta (2017), traz outros argumentos contra a política de cotas como:

Cotas raciais sempre enfrentam o problema de como saber quem pertence ou não de alguém a um grupo racial Pelo sangue? Pela cor da pele? Como o Brasil é um país miscigenado, odiosos tribunais raciais acabam decidindo se alguém pertence ou năo a uma "raça" e ocasionam tremendas injustiças (MANDETTA, 2017, p.6 apud EXAME, 2017, n. p)

Nessa citação, as comissões verificadoras de autodeclaração acabaram sendo mal interpretadas, devido ao fato de a população relacionar a política de cotas ao genótipo. No entanto, é preciso explicar que a política de cotas e as comissões seguem sua avaliação de acordo com as características fenotípicas do candidato, ou seja, pele, cabelo, nariz, boca, pois compreende-se que o racismo e a discriminação acontecem devido a essas características. Assim sendo, as comissões surgem no intuito de combater possíveis enganos proporcionados pelo desconhecimento da lei ou fraudes, garantindo que a vaga reservada seja destinada para aqueles aos quais a lei se destina.

A luta pela democratização da educação superior por meio das cotas ainda teve que enfrentar denúncias no Ministério Público (MP), devido às fraudes na reserva de vagas, as primeiras instituições que implementaram a comissão verificadora de auto declaração foram acusadas de tribunal racial, sendo proibidas de realizarem as verificações. A brecha utilizada foi o fato da lei citar apenas a necessidade de auto declaração, o que por sua vez, deu margem para que estudantes conseguissem fraudar a política ou, até mesmo, pelo desconhecimento do caráter fenotípico da classificação para o acesso, o que tornou propício que outras pessoas ocupassem o lugar de reserva de vagas estabelecidas pela Lei $n . .12 .711 / 2012$.

No entanto, diante do elevado número de denúncias relacionadas às fraudes nas cotas, a partir de 2018 e por meio da normativa n.․ 4/2018, as comissões verificadoras passaram a atuar com autorização do Tribunal Superior da Justiça (TSJ) nos processos seletivos, com o intuito de que as pessoas que estejam acessando os cursos de graduação ou os concursos públicos sejam aqueles que realmente possuem esse direito garantido pela lei de cotas.

Quanto à miscigenação do Brasil, o mito da democracia racial já foi desvelado, essa harmonia entre a casa grande e senzala proposta por Freire, segundo Ubiali (2004, p.7) "[...], acabaram por difundir uma visão de unidade não conflitante nas quais indivíduos e grupos situados hierarquicamente na sociedade compartilham harmonicamente uma vida social", vida esta que, na realidade, apresenta-se conflituosa, demonstrando a distância da superação desse problema social.

Sobre a questão do aluno egresso das cotas e sua atuação no mercado de trabalho, a pesquisa de Mandetta (2017) encontrou a seguinte citação:

Cotas raciais geram preconceito contra pessoas decentes de todas as origens, que gostariam de ser julgadas pelo seu mérito e não pela cor da sua pele. Elas incentivam um clima sem fim de suspeitas de que o aluno negro cotista ou não - não é competente nem como estudante e nem o será como futuro profissional. Você faria uma cirurgia com um médico cotista? (MANDETTA, 2017, p.6 apud EXAME, 2017, n. p). 
0 estudante que ingressa pela política de cotas participa de todo o processo seletivo, assim como os candidatos das vagas de ampla concorrência. 0 diferencial é que, a partir do momento em que 0 estudante decide optar pelas linhas disponibilizadas pelas cotas, ele concorre com outros estudantes que tiveram as mesmas condições socioeconômicas e culturais que ele, e, portanto, o processo tem por finalidade se tornar mais democrático.

Com relação à competência do profissional, relacionada ao fato de ele ser cotista ou não, essa asserção nada mais é do que uma forma de demonstrar o preconceito existente na sociedade, uma vez que a qualificação profissional está relacionada com a relação do indivíduo com a escolha da profissão e o meio como ele se prepara para assumi-la, independentemente de seu fenótipo. Algumas pesquisas apontam dados demonstrando que os estudantes cotistas são mais dedicados que os estudantes de ampla concorrência, por passar por condições de dificuldade valorizam ter acesso ao curso de graduação concluindo com muito êxito na maioria dos casos (ARAUJ O, 2013). Para Munanga (2003, p. 42), "discriminar os negros no mercado de trabalho pelo fato de eles terem estudado graças às cotas é simplesmente deslocar o eixo do preconceito e da discriminação presentes na sociedade que existem sem cotas ou com cotas".

Quadro 2- Argumentos a favor da política de cotas

\begin{tabular}{|c|c|c|}
\hline Fonte/Referência & Argumentos & Lei \\
\hline $\begin{array}{l}\text { G1- } \\
<\text { <ttp://g1.globo.com/educac } \\
\text { ao/noticia/cotas-sociais-em- } \\
\text { universidades-tem-54-de- } \\
\text { aprovacao-diz- } \\
\text { pesquisa.ghtml> }\end{array}$ & $\begin{array}{l}\text { O Brasil passou de uma exclusão social } \\
\text { quase completa no ensino superior, até } \\
\text { pouco tempo ascamadas popularesnão } \\
\text { tinham acesso às universidades } \\
\text { importantes.nesseponto devista, houve } \\
\text { umarevolução. }\end{array}$ & $\begin{array}{l}\text { A lei é destinada as camadas } \\
\text { populares. Como aponta o art. 1.o } \\
\text { que dá o recorte de renda à lei. } \\
\text { Trata-os com diferencial, dando } \\
\text { incentivo para adentraram nas } \\
\text { universidades porque esse } \\
\text { incentivo antes não era dado. }\end{array}$ \\
\hline $\begin{array}{l}\text { G1- } \\
<\text { http://g1.globo.com/educac } \\
\text { ao/noticia/cotas-sociais-em- } \\
\text { universidades-tem-54-de- } \\
\text { aprovacao-diz- } \\
\text { pesquisa.ghtml> }\end{array}$ & $\begin{array}{l}\text { Os casos concretos de racismo que são } \\
\text { colocados por estudantes, professores, } \\
\text { jogadores, incidem no clima de que faz } \\
\text { sentido ter políticas raciais. As pessoas } \\
\text { admitem que há um problema de } \\
\text { racismo }\end{array}$ & $\begin{array}{l}\text { A lei traz a preferência no } \\
\text { preenchimento de vagas negros, } \\
\text { pardos, indígenas e deficientes } \\
\text { visando à inserção dos mesmos na } \\
\text { comunidade acadêmica, para que } \\
\text { assim, possa haver diminuição do } \\
\text { problema de racismo apontado. }\end{array}$ \\
\hline $\begin{array}{l}\text { G1- } \\
\text { <http://g1.globo.com/educac } \\
\text { ao/noticia/cotas-sociais-em- } \\
\text { universidades-tem-54-de- } \\
\text { aprovacao-diz- } \\
\text { pesquisa.ghtml> }\end{array}$ & $\begin{array}{l}\text { É preciso fazer da educação superior um } \\
\text { bem mais democraticamente } \\
\text { distribuído. }\end{array}$ & $\begin{array}{l}\text { Visando essa democratização das } \\
\text { vagas o art. 1.o destina as cotas para } \\
\text { estudantes que cursaram o ensino } \\
\text { médio em escolas públicas e com } \\
\text { renda inferior a um salário mínimo } \\
\text { e meio. } 0 \text { art. 3.o da preferência } \\
\text { dessas vagas a negros, pardos, } \\
\text { indígenas e deficientes. A } \\
\text { proporção das vagas destinadas a } \\
\text { estes é a mesma proporção deles } \\
\text { na população. }\end{array}$ \\
\hline
\end{tabular}




\begin{tabular}{|c|c|c|}
\hline $\begin{array}{l}\text { G1- } \\
<\text { http://g1.globo.com/educac } \\
\text { ao/noticia/cotas-sociais-em- } \\
\text { universidades-tem-54-de- } \\
\text { aprovacao-diz- } \\
\text { pesquisa.ghtml> }\end{array}$ & $\begin{array}{l}\text { "No Brasil, foram } 354 \text { anos de escravidáo, } \\
\text { população negra escravizada } \\
\text { trabalhando para enriquecer a branca. } \\
\text { No pós-abolição, no processo de } \\
\text { industrialização do Brasil, incentivou-sea } \\
\text { vinda dos imigrantes europeus pra cá. } \\
\text { Muitos inclusive receberam terras do } \\
\text { Estado brasileiro, ou seja, foram } \\
\text { beneficiados por ação afimativa para } \\
\text { iniciarem suas vidas por aqui. Tiveram } \\
\text { acesso atrabalho remunerado e, se hoje } \\
\text { a maioria de seus descendentes } \\
\text { desfrutam de uma realidade confortável } \\
\text { foi porqueforamajudadospelo govemo } \\
\text { pra isso. Em contrapartida, para a } \\
\text { população negra não se criou } \\
\text { mecanismos de inclusão. Das } \\
\text { senzalas fomos para as favelas. Se } \\
\text { hoje a maioria da população negra } \\
\text { é pobre é por conta dessa herança } \\
\text { escravocrata e por falta da criação } \\
\text { desses mecanismos". }\end{array}$ & $\begin{array}{l}\text { A lei de cotasé um mecanismo para } \\
\text { que as populações, que antes não } \\
\text { tiveram incentivos para viver bem } \\
\text { no Brasil, sejam incluídas na } \\
\text { sociedade e não mais } \\
\text { marginalizadas. }\end{array}$ \\
\hline
\end{tabular}

Fonte: MANDETTA, 2017.

Os argumentos apresentados evidenciam que 0 acesso à educação superior no Brasil esteve sempre destinado a um público com maior poder aquisitivo, evidenciando a necessidade de meios de acesso mais democráticos, e o posicionamento dos entrevistados ainda trazem a afirmação da existência do racismo (sendo que a visão inferiorizada da raça negra, oriunda da escravidão, ainda se faz fortemente presente na sociedade) e reconhecem a importância das políticas raciais, a necessidade de fomentar o diálogo com as crianças sobre as diferenças em suas diversas formas raciais, gêneros e culturas como meio de combater o racismo e outras formas de discriminação desde a infância.

As pesquisas de doutorado e mestrado que discutem sobre a implementação das cotas nas diferentes IES públicas do país, apresentam aspectos positivos com relação à medida, em sua maioria é possível observar que os negros têm conseguido acessar a educação superior por meio da ação afirmativa, resultando no aumento do número de negros/as nos cursos de graduação. Importante destacar essas pesquisas para que sejam divulgadas e consideradas pelas autoridades do governo como meio de comprovar a eficácia da lei para a democratização do acesso.

A partir do Censo de Educação Superior (CES) do Instituto Nacional de Estudos e Pesquisas Educacionais Anísio Teixeira (INEP), com recorte temporal entre os anos de 2013-2017, portanto após a implantação da Lei de Cotas e destacando apenas IES públicas, foi possível desenvolver o seguinte gráfico: 
Gráfico 4- Matrículas em Cursos de Graduação Presenciais e a Distância por Cor / Raça em IES públicas 2013-2017

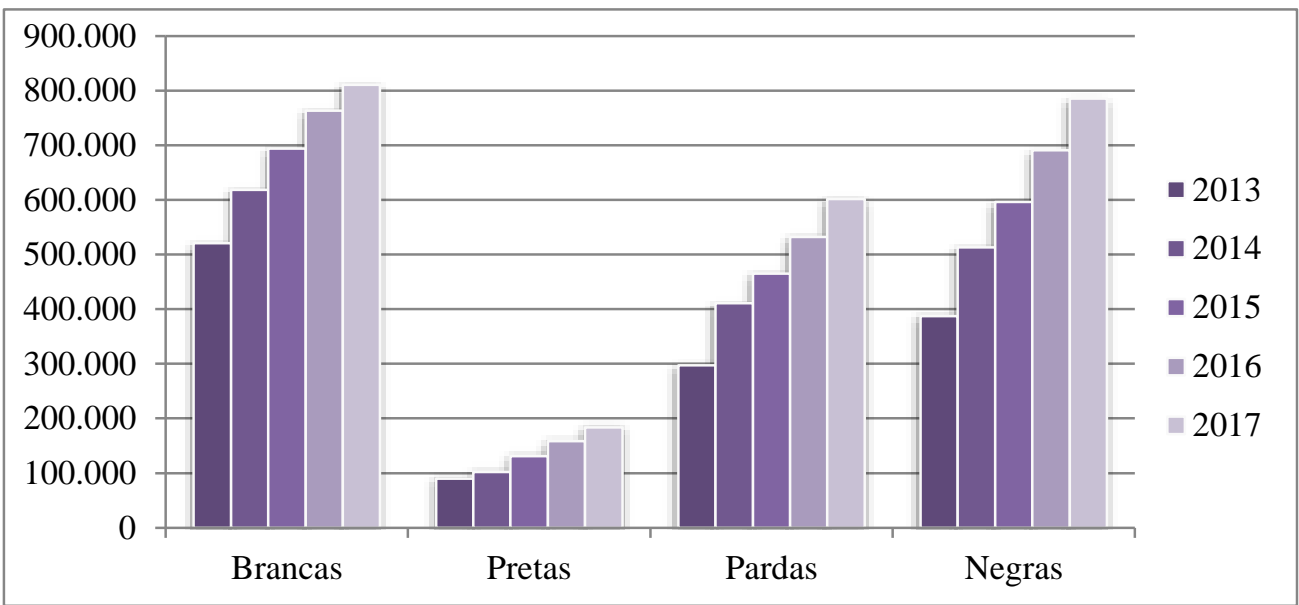

Fonte: INEP/CES, 2013-2017. Organizado por: EVANGELISTA, 2018.

Por meio da análise da matrícula dos estudantes nas IES públicas e segundo cor/raça entre os anos de 2013 a 2017, portanto após a implantação da Lei de Cotas, foi possível observar que houve um progressivo aumento em todas as categorias, visto que a política de cotas consegue ating ir a população branca por meio do recorte de renda dos estudantes oriundos de ensino médio público.

As desigualdades entre brancos e pretos ainda se mantêm em evidência, representando ao longo dos anos uma diferença percentual na taxa de matrícula entre ambas categorias em torno de $-77.38 \%$ no ano de 2017, quando em 2013 a diferença percentual era de $-82.70 \%$, demonstrando assim que houve uma diminuição na taxa de matrícula durante os cinco anos de implantação da política e cotas analisados.

A população parda apresenta resultados da taxa de matrícula maior que a população preta e mais próxima da população branca, essa diferença pode ser um resultado oriundo do maior número de pessoas pardas $46,9 \%$ quando a população preta corresponde a $8,2 \%$, já a população branca representa $42,2 \%$ segundo dados do IBGE (2017).

Em um contexto histórico-social, a auto declaração como pardo é oriunda do período pós-escravidão, um meio que os descendentes de escravos encontraram para diminuir a negatividade atribuída socialmente ao africano escravizado e assim aproximarse da raça branca por meio da miscigenação.

A auto-identificação como pardo, e não mais como negro ou preto, foi a forma encontrada pelos libertos para afirmarem a experiência de liberdade que se abria aos homens livres despossuídos. Por isso, é possível ao Instituto Brasileiro de Geografia e Estatística (IBGE) agregar pretos e pardos na categoria negros. Seja pardo ou preto pertencem à raça negra (GARCIA, 2007, p. 31). 
É possível então, por meio desse contexto histórico-social e devido à miscigenação, agrupar os pretos e pardos na categoria negros. Assim, no GRÁFICO 4 a população negra representa a soma da taxa de matrícula da população de pretos e pardos, ao somar as duas categorias percebemos uma mudança significativa, enquanto a diferença percentual entre brancos e negros em2013 era de $-25.64 \%$, em 2017 essa diferença diminuiu para-3.16\%com relação a população branca, fato que demonstra a necessidade da continuação das políticas afirmativas ao longo dos anos com o intuito de diminuir as diferenças, principalmente as diferenças oriundas da cor/raça da população.

\section{CONSIDERAÇÕES FINAIS}

A partir da discussão, foi possível afirmar que o acesso de estudantes negros/as é prejudicado por fatores socioeconômicos e históricos que os colocam, em comparação com os estudantes brancos, em condições inferiores de acesso à educação superior. A política de cotas representa um meio para que esses estudantes possam competir pelas vagas, nesse nível de educação, com aqueles que tiveram as mesmas condições históricas, culturais e socioeconômicas tornando, portanto, o processo seletivo mais digno.

A partir dos dados pesquisados observa-se que a ação afirmativa é necessária para legitimar o acesso dos negros em cursos de educação superior e tem minimizado algumas desigualdades de acesso entre brancos e negros, como foi possível observar a partir do GRÁFICO 4. Assim, pode-se atribuir esse avanço à política de cotas como também à reafirmação da identidade negra nos últimos anos, pois, segundo o IBGE (2017), tem crescido significativamente o número de pessoas que se autodeclaram como negras.

As condições de vulnerabilidade dos estudantes negros relacionadas à renda apresentam altos índices de desigualdades, e esses estudantes apresentam maior dificuldade de acesso à educação superior, bem como aumentam as chances de evasão do curso, tendo em vista suas condições econômicas e sociais. Compreende-se, assim, que políticas de acesso devem vir acompanhadas de políticas de permanência específicas para esses públicos.

Os argumentos favoráveis e desfavoráveis à política de cotas expressam 0 preconceito e os avanços com relação ao conhecimento sobre esse processo de seleção, assim como a respeito às características que determinam esses grupos de estudantes. As ações afirmativas mudam o cenário da educação superior, favorecendo o aumento de estudantes negros que, em decorrência de um curso superior concluído, terão maiores possibilidades de alterar suas condições concretas de qualidade de vida, tanto pelo acesso ao mercado de trabalho quanto pelo acesso ao conhecimento.

A luta no combate à desigualdade e pobreza por meio da política de cotas como ação afirmativa, tem seu término previsto para o ano de 2022, e diante do cenário eleitoral político atual pode ser uma política que não seja prorrogada, podendo estagnar todo processo de desenvolvimento alcançado desde 2013 a 2017. 


\title{
QUOTA POLICY IN HIGHER EDUCATION: STRUGGLES AND CHALLENGES IN COMBATING POVERTY AND INEQUALITY OF BLACK STUDENTS
}

\begin{abstract}
This article aims to establish a discussion about the vulnerability situation of black students and emphasize the importance of quota policy as a way to democratize the access of these young people to higher education, the methodology Used for the production will be through bibliographic analysis and public data that allow to relate the context of education and poverty with discussions about access to higher education of black people. From the discussion it was possible to observe that the access of black students is impaired by socio-economic and historical factors that put them in comparison with white students in lower conditions of access and the policy of quotas represents a means So that these students can compete for vacancies in higher education with those who have had the same conditions, thus making the selective process more dignified.
\end{abstract}

KEYWORDS: Black students. Higher education. Access. Inequality.

\section{POLÍTICA DE CUOTASEN LA EDUCACIÓN SUPERIOR: LUCHASY DESAFÍOS EN LA LUCHA CONTRA LA POBREZA Y LA DESIGUALDAD DE LOS ESTUDIANTES NEGROS}

RESUMEN: Este artículo pretende establecer una discusión sobre la situación de vulnerabilidad de los estudiantes negros y enfatizar la importancia de la política de cuotas como una manera de democratizar el acceso de estos jóvenes a la educación superior, la metodología Utilizado para la producción será a través del análisis bibliográfico y de los datos públicos que permitan relacionar el contexto de la educación y la pobreza con discusiones sobre el acceso a la educación superior de los negros. De la discusión fue posible observar que el acceso de los estudiantes negros está deteriorado por factores socioeconómicos e históricos que los ponen en comparación con los estudiantes blancos en condiciones de acceso más bajas y la política de cuotas representa un medio Para que estos estudiantes puedan competir por las vacantes en la educación superior con los que han tenido las mismas condiciones, haciendo así el proceso selectivo más dignificado.

PALABRAS CLAVE: Estudiantes negros.; Educación superior. Acceso. Desigualdad.

\section{REFERÊNCIAS}

ALMEIDA, C. E. M. O discurso de inclusão nas políticas de educação superior (20032008)186 f.; 30 cm. Campo Grande - MS, 2009.

ARAÚJ O, I. E. de. Análise socioeconômica das qualidades de cotas para negros na Universidade de Brasilia. 2013. 131 f., il. Dissertação (Mestrado Profissional em Economia do Setor Público) - Universidade de Brasília, Brasília, 2013. 
BITTAR, M.; CORDEIRO, M. J. J . A.; ALMEIDA, C. E. M. Política de Cotas para Negros na Universidade Estadual de Mato Grosso do Sul-um estudo sobre os fatores da permanência. Série-Estudos - Periódico do Mestrado em Educação da UCDB. Campo Grande - MS, n. 24, p. 143-156, jul./dez. 2007.

CASTEL, R. As metamorfoses da questão social: uma crônica do salário. Tradução Iraci D. Poleti. Petrópolis, RJ : Vozes, 2003.

CORDEIRO, A. L. A. Políticas de Ação Afirmativa:Implicações na trajetória acadêmica e profissional de afro-brasileiros/as cotistas egressos/as da UEMS (2007-2014). Campo Grande/MS, 2017. 262p. Tese (Doutorado em Educação) - Universidade Católica Dom Bosco.

DUARTE, N. S. Política Social:Um Estudo Sobre Educação e Pobreza. Brasília, 2012. 256 f. GARCIA, R. C. Identidade fragmentada: um estudo sobre a história do negro na educação brasileira: 1993-1995. Brasília: INEP, 2007.

IBGE-Instituto Brasileiro de Geografia e Estatística. População chegaa 205,5 milhões, commenosbrancose maispardose pretos.Disponível em: «https:/agenciadenoticias.ibge.gov.br/agencia-noticias/2012agencia-de-noticias/noticias/18282-pnad-c-moradores>.Acesso em:23out2018.

INEP - Instituto Nacional de Estudos e Pesquisas Educacionais Anísio Teixeira. Censo da Educação Superior 2013-2017. Brasília: Inep, 2018. Disponível em: <http://portal.inep.gov.br/web/guest/educacao-superior>. Acesso em 20 out. 2018.

IPEA - Instituto de Pesquisa Econômica aplicada. Organizado por: Paulo Roberto. Evolução do Acesso de Jovens à Educação Superior no Brasil. Braślia, 2014.

MACEDO, K. R. A Institucionalização da política de cotas na educação superior na UFMS2013 a 2016. Campo Grande - MS, Dissertação (Mestrado em Educação) 192 f. 30 cm.

MANDETTA. T. Trabalho de finalização da disciplina Relações Étnico Raciais. Curso de Química, Universidade Federal de Mato Grosso do Sul - UFMS, Campo Grande, 2017.

MUNANGA, K. Políticas de ação afirmativa em benefício da população negra no Brasil: um ponto de vista em defesa de cotas. Sociedade e Cultura, v. 4, n. 2, jul./dez. 2001, p. 31-43.

ROUSSEAU, J. Discurso sobre a origem e os fundamentos da desigualdade entre os homens. In: Coleção Os Pensadores. Nova Cultural. São Paulo/SP, 1989.

SISS, A. Afro-brasileiros, políticas de ação afirmativa e educação: algumas considerações. GT 21- ANPED- Relações Étnico-Raciais e Educação, 2003. Disponível 
em:<http://files.ufgd.edu.br/arquivos/arquivos/78/neab/siss\%20ahyas.\%20afrobrasileiro s\%20politicas\%20de\%20acao\%20afirmativa\%20e\%20educaca\%20algumas\%20consider acoes.pdf>Acesso em: 19 set. 2018.

UBIALI, M. P. Ideologia e política: a relação entre Estado e movimento social negro.2004. 230 f. Dissertação (Mestrado em Ciências Humanas) - Universidade Federal de São Carlos, São Carlos, 2004.

Joelma InÊS Evangelista: Mestranda em Educação pela Universidade Federal de Mato Grosso do Sul. Especialista em didática e metodologia no ensino de história, 2014. Graduada em história pelas Faculdades Integradas de Cassilândia, 2013. Membro do Grupo de Estudos e Pesquisas em Políticas de Educação Superior/ Mariluce BittarGEPPES/MB

ORCID: http://orcid.org/0000-0001-9638-5037

E-mail: Joelma_ines@hotmail.com

Carina Elisabeth MACIEL: Pós-doutorado em Educação pela UNEMAT em 2016, atua no Programa de Pós-Graduação em Educação, desenvolve atividades na educação a distância e em cursos de graduação presenciais da mesma instituição. Atua na área de educação, com ênfase em politicas de educação superior e educação especial. Pesquisadora da Rede Universitas/Br na qual participa do Projeto Integrado Políticas, Gestão e Direito à Educação Superior: novos modos de regulação e tendências em construção. É coordenadora do Grupo de Estudos e Pesquisas em Políticas de Educação Superior / Mariluce BittarGEPPES/MB. Coordenadora do Grupo de Estudos e Pesquisas em Inclusão e Educação Especial - GEPIEE. Atualmente atua na coordenação da seção estadual da Associação Nacional de Política e Administração da Educação - ANPAE de Mato Grosso do Sul. OrCID: http://orcid.org/0000-0003-3765-3139

E-mail: carina22em@gmail.com

Este periódico utiliza a licença Creative Commons Attribution 3.0, para periódicos de acesso aberto (Open Archives Iniciative - OAI). 